\title{
The Effect of Aging on Composition and Surface of Translucent Zirconia Ceramic
}

\section{Utjecaj starenja na sastav i površinu translucentne cirkonij- oksidne keramike}

\author{
${ }^{1}$ Polyvalent Dental Office, 10000 Zagreb, Croatia \\ Polivalentna stomatološka ordinacija, Zagreb, Hrvatska \\ 2 Faculty of Graphic Arts, 10000 Zagreb, Croatia \\ Grafički fakultet Sveučilišta u Zagrebu, Zagreb, Hrvatska \\ ${ }^{3}$ Ruđer Bošković Institute, 10000 Zagreb, Croatia \\ Institut Ruđer Bošković, Zagreb, Hrvatska \\ 4 Faculty of Mechanical Engineering and Naval Architecture, 10000 Zagreb, Croatia \\ Fakultet strojarstva i brodogradnje Sveučilišta u Zagrebu, Zagreb, Hrvatska \\ ${ }^{5}$ School of Dental Medicine University of Zagreb \& Dental Clinic, University Hospital Centre Zagreb, 10000 Zagreb, Croatia; \\ Stomatološki fakultet Sveučilišta u Zagrebu i Klinika za stomatologiju Kliničkoga bolničkog centra Zagreb, Hrvatska
}

\section{Abstract}

Objectives: To examine the effect of two aging protocols on the chemical and phase composition as well as the surface state of monolithic translucent zirconia ceramics. Material and Methods: Translucent zirconia ceramics KATANA-Zirconia STML with different surface treatments (no treatment, K1, K2; glazed, G1-G8; polished, P1-P8) underwent testing in order to examine how the two aging protocols (three-hour hydrothermal degradation in an autoclave at $134^{\circ} \mathrm{C}$ and 2 bars: G1-G4, P1-P4, and sixteen-hour chemical degradation in four-percent acetic acid at $80^{\circ} \mathrm{C}$ (ISO 6872): G5-G8, P5-P8) affect chemical composition, particularly the share of stabilizing yttrium oxide (Energy Dispersive $X$ Ray Fluorescence - EDXRF), phase composition (X-ray diffraction - XRD) and surface state in terms of roughness and gloss. Results: Aging protocols did not affect the tested chemical composition stability of specimens and a high share of stabilizing yttrium-oxide ( $\geq 10 \%$ of total content), which correlates with the absence of monoclinic phase. A decrease in gloss on all specimens is statistically significant. Chemical degradation substantially increased the surface roughness of tested specimens. Conclusions: Translucent monolithic zirconia demonstrated a stable chemical composition and resistance to tetragonal-to-monoclinic transformation. Surface gloss was significantly reduced, especially in polished specimens. Contrary to glazed specimens, the tested polished specimens manifested an increase in surface roughness. Glazing the surface of translucent monolithic zirconia produces better esthetic, tribological and hygienic effects than polishing.
Received: September 1st, 2020

Accepted: November 2nd, 2020

Address for correspondence

Professor Ketij Mehulić

University of Zagreb

School of Dental Medicine

Department of Prosthodontics

Gundulićeva 5, 10000 zagreb

mehulic@sfzg.hr

Key words

Zirconia; Dental Materials; Materials

Testing; Surface Properties; Dental Polishing

\section{Introduction}

For several years, zirconia based ceramics has been the material of choice in the fabrication of fixed partial dentures (FPD), especially for the more strain-prone posterior region of dental arch, because of its good mechanical properties (flexural strength 900-1,200 MPa, hardness HV0.1 1200) (1). Due to insufficient translucency, it has been unable to meet high esthetic criteria for usage in the restoration of the anterior part of dental arch (2). For that reason, it has been veneered with ceramic materials that have better optical properties (glass and feldspathic ceramics) (1-3).

Two problems have arisen in the clinical application of this material. One problem is common to all bilayer systems and is caused by a discord in the thermal expansion coefficient between the veneering material and the core materi-
Uvod

Cirkonij-oksidna keramika već je godinama materijal izbora za izradu fiksnoprotetičkih nadomjestaka (FPN) s posebnim naglaskom na primjenu u stražnjoj regiji zubnog niza zbog dobrih mehaničkih svojstava (savojna čvrstoća 1200 MPa, tvrdoća HV0.1 1200) (1). Zbog nedovoljne translucencije nije zadovoljavala visoke estetske kriterije u sanaciji prednjeg dijela zubnog niza (2). Zbog toga se oblagala keramikama boljih optičkih svojstava (staklokeramike i glinična keramika) $(1-3)$.

U kliničkoj primjeni pojavljivala su se dva problema. Jedan je zajednički svim dvoslojnim sustavima i nastaje zbog neusklađenosti koeficijenata toplinske istezljivosti obložne keramike i keramike od koje je izrađena osnovna konstrukcija. Posljedica te neusklađenosti jest pojava napetosti u sla- 
al. Because of this discord, strain is exerted on the "weaker" material, which may result in chipping of the veneering material (4-6). Another big problem is aging (low temperature degradation - LTD - spontaneous tetragonal-to-monoclinic transformation of crystal structure in a moist medium at room temperature) (7-10). The transformation of crystal structure generates the expansion of grain volume (4-5\%) (10-12). Grain growth exerts strain on grain boundaries (1114), which may lead to microcracks in the material and, once critical fracture toughness has been exceeded, prosthetic restoration fracture (11-14). Spontaneous phase transformation of zirconia ceramics is inhibited by adding various shares of stabilizers (yttrium, calcium, magnesium or cerium oxide) $(8$, 9, 14). Simultaneously, the expansion of the volume of grains volume and transformation toughening (closing cracks) provide these materials with a high value of flexural strength. The scientific and expert communities have been making efforts to eliminate the aforementioned problems and improve zirconia materials while maintaining their good properties. Through multi-parameter experimental protocols, they have endeavored to examine the long-term behavior of materials in the oral cavity as realistically as possible by analyzing both mechanical and esthetic properties. Improving the esthetic quality of these materials extends their application to the anterior region of dental arch. The most recent research studies indicate that optical properties of zirconia ceramics could be improved by increasing the share of transformation-resistant cubic crystalline structure (15-18).

Aside from microstructure, surface state also has a great impact on optical properties (19-22). Due to specular reflection, shiny and glossy surfaces seem lighter and fresher, whereas unpolished and rough surfaces appear darker and more saturated (19-22). Tribological relations of opposite substrates also give importance to surface state (23-27). Greater surface roughness of previous generations of zirconia ceramics and the consequential greater consumption of antagonists in the chewing process were caused by phase transformation and the ensuing presence of the monoclinic phase; as crystals in that phase had a larger volume than crystals in the tetragonal phase, they rose above the surface of the material (8-15). In their extensive review of relevant literature, Passos et al. highlighted the importance of polishing zirconia fixed partial dentures, noting that enamel abrasion of antagonist teeth in such tribo-pairs is reduced to a minimum (23). Sripetchdanond et al. formed a tribo-pair made up of tooth enamels with monolithic zirconia ceramics and glass ceramics, respectively, and found that the former material wore a natural tooth out much less than the latter (24). Another important factor in plaque control should not be ignored - the manner and quality of the final surface treatment on a restoration (28).

The aim of this research was to investigate how aging protocols affect chemical composition (in particular, the share of stabilizing yttrium oxide), phase composition and the manifestation of tetragonal-to-monoclinic transformation as well as surface state (conveyed as surface gloss and surface roughness).

The following hypotheses were tested: the new generation of zirconia material contains a share of yttrium oxide that correlates with structural stability, i.e. the absence of te- bijem materijalu koja može završiti lomom obložne keramike $(4-6)$. Drugi veliki problem je starenje (degradacija pri niskim temperaturama - LTD - spontana transformacija tetragonske kristalne strukture u monoklinsku u vlažnom mediju pri sobnoj temperaturi) $(7-10)$. Posljedica transformacije kristalne strukture volumna je ekspanzija zrna (4 - 5\%) $(10-12)$. Rast zrna stvara naprezanje na njegovim granicama $(11$ - 14) koje može prouzročiti mikropukotine u materijalu, odnosno kada se prekorači kritična lomna žilavost lom nadomjeska $(11-14)$. Dodavanjem stabilizatora u različitom postotku (itrijev, kalcijev, magnezijev ili cerijev oksid) sprječava se spontana fazna transformacija cirkonij-oksidne keramike $(8,9,14)$. Volumna ekspanzija zrna također je razlog za visoke vrijednosti savojne čvrstoće prve i druge generacije materijala zahvaljujući fenomenu transformacijskog očvršćenja $(8-14)$. Pokušavajući poboljšati postojeće cirkonij-oksidne materijale, na tržištu se pojavio veći broj sustava cirkonij-oksidne keramike upitne kvalitete, što znanstvenoj i stručnoj zajednici nameće potrebu za njihovom kvalitetnijom analizom. Različitim eksperimentalnim protokolima nastoje što vjernije, na temelju više parametara, ispitati njihovo ponašanje u ustima tijekom duljeg razdoblja. Uz mehanička svojstva u fiksnoj su protetici itekako važna i optička svojstva. Poboljšanje estetike takvih materijala proširuje njihovu primjenu i na prednji dio zubnoga niza. Bolja optička svojstva novijih cirkonij-oksidnih keramika postignuta su većim udjelom transformacijski otpornije kubične kristalinične strukture $(15-18)$.

No na optička svojstva uvelike utječe i kvaliteta površine $(19-22)$. Zbog zrcalne refleksije se sjajne i glatke površine doimaju svjetlijima i svježijima, za razliku od nepoliranih i hrapavih površina koje izgledaju tamnije i zasićeno (1922). Kvaliteta površine važna je i zbog triboloških odnosa nasuprotnih supstrata $(23-27)$. Veća hrapavost površine prethodnih generacija cirkonij-oksidne keramike, te posljedično veće trošenje antagonista u funkciji nastajalo je zbog fazne transformacije i posljedično prisutnosti monoklinske faze čiji kristali imaju veći volumen od tetragonskih zbog čega su se izdizali iznad površine materijala $(8-15)$. Passos i suradnici u svojem su istraživanju istaknuli da je trošenje cakline nasuprotnih zuba minimizirano u kontaktu s visoko poliranim cirkonij-oksidnim nadomjestkom (23). Sripetchdanond i suradnici pokazali su u svojoj studiji da monolitna cirkonijoksidna keramika mnogo manje troši prirodni zub u odnosu prema staklokeramičkim nadomjestcima (24). Ne smije se zanemariti da je način i kvaliteta završne obrade površine nadomjestka bitan čimbenik u kontroli plaka (28).

Svrha ovog istraživanja jest ispitati utjecaj protokola starenja na kemijski sastav, osobito udio stabilizatora itrijeva oksida, na fazni sastav i pojavnost tetragonsko-monoklinske transformacije i na stanje površine izraženo njezinim sjajem i hrapavošću.

Testirat će se sljedeće hipoteze: novija generacija materijala cirkonij-oksidne keramike sadržava udio itrijeva oksida koji je u korelaciji sa stabilnošću strukture, odnosno s eliminacijom tetragonsko-monoklinske fazne transformacije. Eksperimentalni protokoli starenja neće dovesti do fazne transformacije, niti ce smanjiti udio stabilizatora itrijeva oksida 
tragonal-to-monoclinic phase transformation. Experimental aging protocols will cause neither phase transformation nor a decrease in the share of stabilizing yttrium oxide in the material. Experimental aging protocols will have an effect on the surface gloss of the specimens. Experimental aging protocols will have an effect on the surface roughness of the specimens.

\section{Material and methods}

\section{Specimen Preparation}

The material employed in this research was a monolithic zirconia based ceramics KATANA-Zirconia Super Translucent Multi Layered - STML (Kuraray Noritake Dental Inc., Tokyo, Japan), shade A2. Using the CAD/CAM technology (Zenotec Easy Wieland Dental, Pforzheim, Germany), 18 disc-shaped specimens $(11 \times 11 \times 1.5 \mathrm{~mm}$ with $\pm 5 \%$ tolerance) were fabricated. The specimens were sintered in a furnace (Wieland, Pforzheim, Germany) at $1,550{ }^{\circ} \mathrm{C}$ for two hours according to manufacturer's instructions. The temperature was increased until the sintering temperature was reached and then decreased in the cooling process after the final sintering at a rate of $10{ }^{\circ} \mathrm{C} / \mathrm{min}$. The specimens were divided into two groups, according to the final surface treatment applied: eight specimens were glazed following the manufacturer's instructions (G1-G8), whereas eight specimens were polished with rubber (Ceragloss, EDENTA AG, Switzerland) accompanied by water cooling (P1-P8). The remaining two specimens served as control specimens in the research and received no surface treatment (K1, K2) (Figure 1).

\section{Measurements and Analyses}

All measurements and analyses of the specimens were conducted in two phases: before and after experimental aging protocols.

Two specimens (K1, P2) were analyzed using Energy Dispersive X-ray Fluorescence (EDXRF) (Ruđer Bošković Institute, Zagreb, Croatia). A Philips W X-ray tube (Philips Co., Amsterdam, Netherlands) was utilized as a source. The specimens were irradiated by the secondary Mo target in rectangular geometry. The signal was detected using a semiconductor SiLi detector (Canberra Packard, Vienna, Austria) with $30 \mathrm{~mm}^{2}$ of active surface area and a thickness of $3 \mathrm{~mm}$. The thickness of beryllium window of the detector was $0.025 \mathrm{~mm}$ and the resolution at $5.9 \mathrm{keV}$ was $170 \mathrm{eV}$ (FWHM). The working parameters were $35 \mathrm{kV}$ and $5 \mathrm{~mA}$ in a 100 -bar vacuum. The measurement period was $100 \mathrm{~s}$. The samples were analyzed for $\mathrm{Y}_{2} \mathrm{O}_{3}, \mathrm{ZrO}_{2}, \mathrm{HfO}_{2}$ as well as $\mathrm{Sr}$ and $\mathrm{Zn}$. Relative errors of measurement, defined as slope coefficient errors for correlation lines were as follows: $\mathrm{Y}_{2} \mathrm{O}_{3}-2.11 \%, \mathrm{ZrO}_{2}-$ $1.84 \%, \mathrm{HfO}_{2}-2.50 \%, \mathrm{Zn}$ and $\mathrm{Sr}-0.1 \%$. Minimum detection limits (MDL) were: $\mathrm{Y}_{2} \mathrm{O}_{3}-0.11 \%, \mathrm{ZrO}_{2}-1.35 \%$, $\mathrm{HfO}_{2}-0.10 \%, \mathrm{Zn}$ and $\mathrm{Sr}-0.01 \%$.

$\mathrm{X}$-ray diffraction $(\mathrm{XRD})$ was performed on two polished specimens (P1, P5) with a diffractometer (Philips PW 1820, Philips Co., Amsterdam, Netherlands) in order to attain the initial crystal structure. These two specimens (P1, P5) were subjected to $\mathrm{CuK}$-alpha radiation in the space between $10^{\circ}$ and $70^{\circ}$ of the 2theta angle, with a step size of $0.02^{\circ}$ and step u materijalu. Eksperimentalni protokoli starenja utjecat će na sjaj površine uzoraka. Eksperimentalni protokoli starenja utjecat će na hrapavost površine uzoraka.

\section{Materijali i postupci}

\section{Priprema uzoraka}

$\mathrm{U}$ istraživanju je korištena monolitna cirkonij-oksidna keramika KATANA-Zirconia Super Translucent Multi Layered - STML (Kuraray Noritake Dental Inc., Tokio, Japan), boje A2. Izrađeno je 18 uzoraka $(11$ x 11 x $1,5 \mathrm{~mm}$ u toleranciji $\pm 5 \%$ ) CAD/CAM tehnikom (Zenotec Easy Wieland Dental, Pforzheim, Njemačka). Uzorci su sinterirani 2 sata prema uputi proizvođača u peći (Wieland, Pforzheim, $\mathrm{Nje-}$ mačka) na temperaturi od $1550^{\circ} \mathrm{C}$. Porast temperature iznosio je $10{ }^{\circ} \mathrm{C} / \mathrm{min}$. do temperature sinteriranja te je jednaka bila i dinamika snižavanja temperature - hlađenja nakon završenog sinteriranja. Ovisno o završnoj obradi površine uzorci su podijeljeni u dvije skupine: osam uzoraka glazirano je prema uputi proizvođača (G1 - G8), a osam polirano gumicama (Ceragloss, EDENTA AG, Švicarska) uz vodeno hlađenje (P1 - P8). Preostala dva uzorka bili su kontrolni i nisu površinski obrađivani $(\mathrm{K} 1, \mathrm{~K} 2)$ (slika 1.).

\section{Mjerenja i analize}

Sva mjerenja i analize na uzorcima provedeni su u dvije faze - prije eksperimentalnih protokola starenja i poslije njih.

Dva uzorka $(\mathrm{K} 1, \mathrm{P} 2)$ analizirana su metodom energetsko disperzivne fluorescencije X-zraka (EDXRF) (Institut Ruđer Bošković, Zagreb, Hrvatska). Kao izvor korištena je Philipsova W rendgenska cijev (Philips Co., Amsterdam, Nizozemska). Uzorci su ozračivani sekundarnim Mo zračenjem u pravokutnoj geometriji. Korišsten je poluvodički SiLi detektor (Canberra Packard, Beč, Austrija), aktivne površine $30 \mathrm{~mm}^{2}$ i debljine $3 \mathrm{~mm}$. Debljina berilijeva prozora iznosi $0,025 \mathrm{~mm}$, a rezolucija na 5,9 keV iznosi $170 \mathrm{eV}$ (FWHM). Radni parametri za ozračivanje meta iznosili su $35 \mathrm{kV}$ i $5 \mathrm{~mA}$ uz vakuum od $10^{\circ}$ bara tijekom $100 \mathrm{~s}$. U uzorcima su analizirani $\mathrm{Y}_{2} \mathrm{O}_{3}$, $\mathrm{ZrO}_{2}, \mathrm{HfO}_{2}$, $\mathrm{Sr}$ i Zn. Relativne pogreške mjerenja određene su kao pogreška koeficijenta nagiba korelacijskog pravca $\mathrm{i}$ iznosile su: $\mathrm{Y}_{2} \mathrm{O}_{3}-2,11 \%, \mathrm{ZrO}_{2}-1,84 \%, \mathrm{HfO}_{2}-2,50 \%$, $\mathrm{Zn}$ i $\mathrm{Sr}-0,1 \%$. Minimalni detekcijski limiti (MDL) iznosili su: $\mathrm{Y}_{2} \mathrm{O}_{3}-0,11 \%, \mathrm{ZrO}_{2}-1,35 \%, \mathrm{HfO}_{2}-0,10 \%, \mathrm{Zn}$ i $\mathrm{Sr}-0,01 \%$.

$\mathrm{Na}$ dva polirana uzorka (P1, P5) učinjena je difrakcijska analiza X-zrakama (XRD) na difraktometru (Philips PW 1820, Philips Co., Amsterdam, Nizozemska) radi dobivanja početne kristalne strukture, uz pretpostavku da je ona ista u svim uzorcima na početku istraživanja. Dva uzorka (P1, P5) mjerena su na CuKalfa zračenju u području 2theta kuta: od 10 do $70^{\circ}$, u koraku od $0,02^{\circ}$ i vremenom prikupljanja od $1 \mathrm{~s} /$ step. 
time of $1 \mathrm{~s} / \mathrm{step}$, because it was assumed that the initial phase composition of all specimens was identical.

A glossmeter (Elcometer 407, Elcometer Inc., Michigan, USA) was utilized in null measurements of the surface gloss on the specimens. Elcometer is a multiangle glossmeter, meaning that light is reflected (detected) off a surface at $20^{\circ}, 60^{\circ}$ and $85^{\circ}$ angles $\left(60^{\circ}\right.$ being the reference angle). Ten measurements were conducted on each specimen (Faculty of Graphic Arts, University of Zagreb, Croatia).

Ten roughness profiles were recorded on specimens G3, G6, P3 and P6 using stylus instrument Perthometer S8P (Perthen Mahr, Göttingen, Germany) under the following conditions:

Gauss filter: $l=0.8 \mathrm{~mm}$

Tip radius: $r=5 \mu \mathrm{m}$

Evaluation length: $l n=4 \mathrm{~mm}$.

Roughness parameters $R_{a}$ and $R_{z}$ were calculated on the recorded profiles. The traceability of measurement results was ensured by Croatian national roughness standards.

Two experimental protocols were conducted in this research. A three-hour hydrothermal degradation was carried out in an autoclave (SKO 7, Faro, Italy) at a temperature of $134^{\circ} \mathrm{C}$ and under a pressure of 2 bars (six 30 -minute cycles), with distilled water. On the other hand, chemical degradation was carried out in a corrosive medium (four-percent acetic acid $\left.\left(\mathrm{CH}_{3} \mathrm{COOH}\right), \mathrm{pH} 2.49\right)$ at $80{ }^{\circ} \mathrm{C}$ over a sixteenhour period (ISO 6872). The specimens were divided into four subgroups according to the experimental protocol they were subjected to. Four glazed specimens (G1-G4) (first subgroup) and four polished specimens (P1-P4) (second subgroup) were sterilized in an autoclave, whereas the remaining four glazed specimens (G5-G8) (third subgroup) and the remaining four polished specimens (P5-P8) (fourth subgroup) were immersed into a corrosive medium in a 1,000-mL glass measuring flask. Instead of being subjected to experimental protocols, control specimens (K1, K2) were kept at a standard temperature of $20^{\circ} \mathrm{C}$ and under a standard pressure of $1 \mathrm{~atm}(101,325 \mathrm{~Pa})$ throughout the study.

The same measurements and analyses from the beginning of the research were made after the aging protocols. One specimen from each subgroup (G2, G6, P2, P6) and control specimen K1 were analyzed using the EDXRF methodology so as to identify the chemical composition of the specimens after aging protocols. The phase composition was determined with a post-aging XRD analysis of one specimen from each subgroup (G1, G5, P1, P5). Surface gloss was measured on all specimens. Post-aging surface roughness was analyzed on the same specimens as at the start of the research.

\section{Analysis of Results}

The results of the research are displayed in tables (chemical composition) and figures (diffraction analyses). In order to statistically analyze the results of surface gloss measurements, a Bonferroni test and an ANOVA (Analysis of Variance) test with a $95 \%$ confidence interval were employed. All $p$ values under 0.05 were considered to be statistically significant. The values of roughness parameters $R$ and $R$ are expressed as arithmetical means of 10 recorded profiles, with
Učinjena su i nulta mjerenja sjaja površine svih uzoraka glosimetrom (Elcometer 407, Elcometer Inc, Michigan, $\mathrm{SAD}$ ). Elcometer je multiangle glosimetar, što znači da se svjetlost $s$ uzorka reflektira (detektira) pod kutovima od $20^{\circ}$, $60^{\circ}$ i $85^{\circ}\left(60^{\circ}\right.$ je korišteno kao referentni kut). Učinjeno je po 10 mjerenja na svakom uzorku (Grafički fakultet Sveučilišta u Zagrebu, Zagreb, Hrvatska).

Na uzorcima G3, G6, P3 i P6 provedeno je snimanje deset profila hrapavosti (Fakultet strojarstva i brodogradnje Sveučilišsta u Zagrebu, Zagreb, Hrvatska) korišstenjem uređaja s ticalom (Perthometer S8P Perthen Mahr, Göttingen, Njemačka) sa sljedećim parametrima:

Gaussov filtar: $l_{\mathrm{c}}=0,8 \mathrm{~mm}$

ticalo radijusa: $r=5 \mu \mathrm{m}$

duljina ocjenjivanja: $\ln =4 \mathrm{~mm}$.

$\mathrm{Na}$ snimljenim profilima računati su parametri hrapavosti $R_{a}$ i $R_{z}$. Sljedivost rezultata mjerenja osigurana je preko državnog etalona hrapavosti RH.

U ovom istraživanju korištena su dva eksperimentalna protokola starenja. Hidrotermalna degradacija provedena je u autoklavu (SKO 7, Faro, Italija) na temperaturi od $134^{\circ} \mathrm{C}$, pri tlaku od 2 bara u trajanju od 3 sata (6 ciklusa po $30 \mathrm{~min}$ ), uz korištenje destilirane vode. Kemijska degradacija provedena je u korozivnom mediju (4-postotna octena kiselina $\left.\left(\mathrm{CH}_{3} \mathrm{COOH}\right)\right) \mathrm{pH}$ vrijednosti 2,49 na $80{ }^{\circ} \mathrm{C}$ tijekom 16 sati (ISO 6872). Uzorci su, ovisno o korištenom eksperimentalnom protokolu starenja, podijeljeni u četiri podskupine. Četiri glazirana uzorka (G1 - G4) (prva podskupina) i četiri polirana uzorka (P1 - P4) (druga podskupina) bili su izloženi sterilizaciji u autoklavu, a preostala četiri glazirana (G5 - G8) (treća podskupina) i četiri polirana uzorka (P5 - P8) (četvrta podskupina) postavljeni su u staklenu mjernu tikvicu volumena $1000 \mathrm{~mL}$, te im je dodan korozivni medij do potpunog uranjanja uzoraka. Kontrolni uzorci nisu izlagani eksperimentalnim protokolima starenja, nego su tijekom istraživanja čuvani na standardnoj temperaturi od $20^{\circ} \mathrm{C}$ pri standardnom tlaku od $1 \mathrm{~atm} / \mathrm{SA}(101325 \mathrm{~Pa})$.

Nakon protokola starenja na uzorcima su provedena identična mjerenja i analize kao i na početku istraživanja. Za odredivanje kemijskog sastava nakon protokola starenja metodom EDXRF analiziran je po jedan uzorak iz svake podskupine (G2, G6, P2, P6) i kontrolni uzorak K1. Za odredivanje faznog sastava metodom XRD nakon protokola starenja analiziran je po jedan uzorak iz svake podskupine (G1, G5, P1 i P5). Mjerenja sjaja obavljena su na svim uzorcima. Za odredivanje površinske hrapavosti nakon protokola starenja analizirani su isti uzorci kao na početku istraživanja.

\section{Analiza dobivenih rezultata}

Rezultati ovog istraživanja prikazani su tabelarno (kemijski sastav) i grafički (difrakcijske analize). Za statističku analizu rezultata mjerenja sjaja korištena je ANOVA - analiza varijance $s$ 95-postotnom pouzdanošću te Bonferronijev test. Sve $p$ vrijednosti manje od 0,05 smatrane su statistički značajnima. Vrijednosti parametara hrapavosti $R$ i $R$ iskazane su kao aritmetičke sredine tih parametara ostvarenih na 10 snimljenih profila te one-way-ANOVA-om. 
the addition of a one-way ANOVA.

\section{Results}

The pre-aging examination of chemical composition on specimens K1 and P2 (Table 1) yielded the following shares (arithmetic mean \pm standard deviation) of chemical compounds: yttrium oxide $11.97 \pm 0.13 \%$; zirconium oxide $85.87 \pm 0.19 \%$; hafnium oxide $2.16 \pm 0.15 \%$. Multiple specimens were not analyzed because the chemical composition of all specimens was found to be identical at the start of the research.

The results of chemical composition after hydrothermal degradation in an autoclave (specimens P2, G2) and chemical degradation in a corrosive medium (specimens P6, G6) are displayed in Table 2 . The difference in the share of chemical elements before and after aging protocols is not a significant one. On the glazed side of glazed specimens, the dif-

\section{Rezultati}

Rezultati ispitivanja kemijskog sastava na početku istraživanja na uzorcima K1 i P2 (tablica 1.) pokazuju sljedeće udjele kemijskih spojeva (aritmetička sredina \pm standardna devijacija): itrijev oksid 11,97 $\pm 0,13 \%$; cirkonijev oksid 85,87 $\pm 0,19 \%$; hafnijev oksid 2,16 $\pm 0,15 \%$. Nije analizirano više uzoraka jer je kemijski sastav isti u svim uzorcima na početku istraživanja.

Rezultati kemijskog sastava nakon hidrotermalne degradacije u autoklavu (uzorci P2, G2) i kemijske degradacije u korozivnom mediju (uzorci P6, G6) prikazani su u tablici 2. Dobivena razlika u udjelu elemenata prije eksperimentalnih protokola i poslije njih nije značajna. Nešto veća razlika u udjelu itrijeva oksida uočena je na glaziranoj strani glaziranih uzoraka $(10,90 \pm 0,30 \%)$ u odnosu prema neglaziranoj strani glaziranih uzoraka $(11,85 \pm 0,00 \%)$. Neglazirane strane glaziranih uzoraka imaju gotovo identične udjele spojeva kao i ostali uzorci.

\begin{tabular}{|c|c|c|c|c|}
\hline $\begin{array}{c}\text { Specimen } \\
\text { Uzorak }\end{array}$ & Description $\bullet$ Opis & $\mathrm{Y}_{2} \mathrm{O}_{3}(\%)$ & $\mathrm{Zr} \mathrm{O}_{2}(\%)$ & $\mathrm{HfO}_{2}(\%)$ \\
\hline K1a & Control specimen - upper surface $\bullet$ Kontrolni uzorak - gornja strana & 11.79 & 85.97 & 2.24 \\
\hline K1b & Control specimen - lower surface $\bullet$ Kontrolni uzorak - donja strana & 12.10 & 85.63 & 2.26 \\
\hline $\mathrm{P} 2 \mathrm{a}$ & Polished specimen - polished surface $\bullet$ Polirani uzorak - polirana strana & 12.01 & 86.06 & 1.94 \\
\hline \multirow[t]{2}{*}{$\mathrm{P} 2 \mathrm{~b}$} & Polished specimen - unpolished surface $\bullet$ Polirani uzorak - nepolirana strana & 11.98 & 85.82 & 2.20 \\
\hline & $\mathrm{AM} \pm \mathrm{SD} \bullet \mathrm{AS} \pm \mathrm{SD}$ & $11.97 \pm 0.13$ & $85.87 \pm 0.19$ & $2.16 \pm 0.15$ \\
\hline
\end{tabular}

Table 2 Post-aging chemical composition of zirconia ceramic KATANA-Zirconia STML.

Tablica 2. Kemijski sastav cirkonij-oksidne keramike KATANA-Zirconia STML nakon protokola starenja

\begin{tabular}{|c|c|c|c|c|c|c|}
\hline $\begin{array}{l}\text { Specimen } \\
\text { Uzorak }\end{array}$ & Description $•$ Opis & $\begin{array}{l}\mathrm{Y}_{2} \mathrm{O}_{3} \\
(\%)\end{array}$ & $\begin{array}{c}\mathrm{ZrO}_{2} \\
(\%)\end{array}$ & $\begin{array}{l}\mathrm{HfO}_{2} \\
(\%)\end{array}$ & $\begin{array}{l}\mathrm{Zn} \\
(\%)\end{array}$ & $\begin{array}{l}\text { Sr } \\
(\%)\end{array}$ \\
\hline $\mathrm{P} 2 \mathrm{a}$ & $\begin{array}{l}\text { Polished specimen - polished surface } \bullet \text { Polirani uzorak - } \\
\text { polirana strana }\end{array}$ & 11.91 & 86.03 & 2.06 & 0 & 0 \\
\hline $\mathrm{P} 2 \mathrm{~b}$ & $\begin{array}{l}\text { Polished specimen - unpolished surface } \bullet \text { Polirani uzorak - } \\
\text { nepolirana strana }\end{array}$ & 11.93 & 85.85 & 2.23 & 0 & 0 \\
\hline P6a & $\begin{array}{l}\text { Polished specimen - polished surface } \bullet \text { Polirani uzorak - } \\
\text { polirana strana }\end{array}$ & 11.77 & 86.31 & 1.92 & 0 & 0 \\
\hline \multirow[t]{2}{*}{ P6b } & $\begin{array}{l}\text { Polished specimen - unpolished surface } \bullet \text { Polirani uzorak - } \\
\text { nepolirana strana }\end{array}$ & 11.91 & 86.14 & 1.95 & 0 & 0 \\
\hline & $\mathrm{AM} \pm \mathrm{SD} \bullet \mathrm{AS} \pm \mathrm{SD}$ & $11.88 \pm 0.07$ & $86.08 \pm 0.19$ & $2.04 \pm 0.14$ & & \\
\hline K1a & $\begin{array}{l}\text { Control specimen - upper surface } \bullet \text { Kontrolni uzorak - } \\
\text { gornja strana }\end{array}$ & 11.75 & 86.22 & 2.04 & 0 & 0 \\
\hline \multirow[t]{2}{*}{$\mathrm{K} 1 \mathrm{~b}$} & $\begin{array}{l}\text { Control specimen - lower surface } \bullet \text { Kontrolni uzorak }- \text { donja } \\
\text { strana }\end{array}$ & 11.74 & 86.29 & 1.97 & 0 & 0 \\
\hline & $\mathrm{AM} \pm \mathrm{SD} \bullet \mathrm{AS} \pm \mathrm{SD}$ & $11.75 \pm 0.01$ & $86.26 \pm 0.05$ & $2.01 \pm 0.05$ & & \\
\hline G2a & $\begin{array}{l}\text { Glazed specimen - glazed surface } \bullet \text { Glazirani uzorak - } \\
\text { glazirana strana }\end{array}$ & 10.68 & 83.23 & 1.21 & 3.38 & 1.5 \\
\hline \multirow[t]{2}{*}{ G6a } & $\begin{array}{l}\text { Glazed specimen - glazed surface } \bullet \text { Glazirani uzorak - } \\
\text { glazirana strana }\end{array}$ & 11.11 & 84.36 & 1.47 & 2.14 & 0.92 \\
\hline & $\mathrm{AM} \pm \mathrm{SD} \bullet \mathrm{AS} \pm \mathrm{SD}$ & $10.90 \pm 0.30$ & $83.80 \pm 0.80$ & $1.34 \pm 0.18$ & $2.76 \pm 0.88$ & $1.21 \pm 0.41$ \\
\hline G2b & $\begin{array}{l}\text { Glazed specimen - non-glazed surface } \bullet \text { Glazirani uzorak - } \\
\text { neglazirana strana }\end{array}$ & 11.85 & 86.35 & 1.8 & 0 & 0 \\
\hline \multirow[t]{2}{*}{ G6b } & $\begin{array}{l}\text { Glazed specimen - non-glazed surface } \bullet \text { Glazirani uzorak - } \\
\text { neglazirana strana }\end{array}$ & 11.85 & 86.31 & 1.85 & 0 & 0 \\
\hline & $\mathrm{AM} \pm \mathrm{SD} \bullet \mathrm{AS} \pm \mathrm{SD}$ & $11.85 \pm 0.00$ & $86.33 \pm 0.03$ & $1.83 \pm 0.04$ & & \\
\hline
\end{tabular}



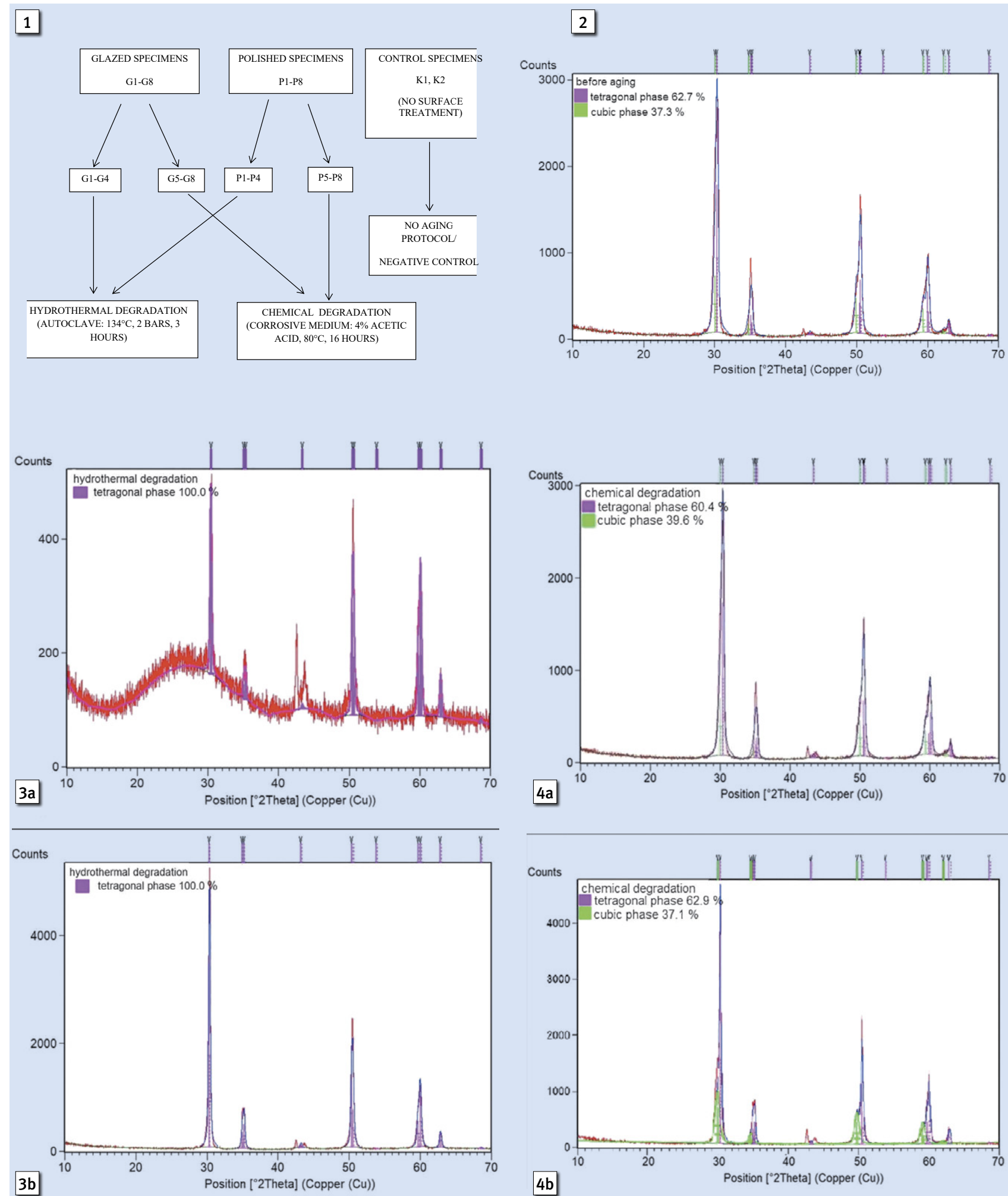

Figure 1 Graphic division of groups of specimens.

Slika 1. Grafički prikaz podjele skupina uzoraka

Figure 2 X-ray diffraction analysis of polished specimens P1 and P5 before aging protocols.

Slika 2. Difrakcijska analiza X-zrakama poliranih uzoraka P1 i P5 prije protokola starenja

Figure 3 X-ray diffraction analysis after aging in an autoclave for glazed specimen G1 (3A) and polished specimen P1 (3B).

Slika 3. Difrakcijska analiza X-zrakama glaziranog uzorka G1 (3A) i poliranog uzorka P1 (3B) nakon starenja u autoklavu

Figure $4 \mathrm{X}$-ray diffraction analysis after chemical degradation in a corrosive medium for glazed specimen G5 (4A) and polished specimen P5 (4B).

Slika 4. Difrakcijska analiza X-zrakama glaziranog uzorka G5 (4A) i poliranog uzorka P5 (4B) nakon kemijske degradacije u korozivnom mediju 
Table 3 Inter-group statistical analysis of surface gloss measurements before and after aging protocols (Bonferroni test with $95 \%$ confidence interval, $p<0.05$ ).

Tablica 3. Statistička analiza vrijednosti sjaja površine prije i poslije protokola starenja između skupina uzoraka (Bonferronijev test s 95-postotnim intervalom pouzdanosti, $p<0,05$ )

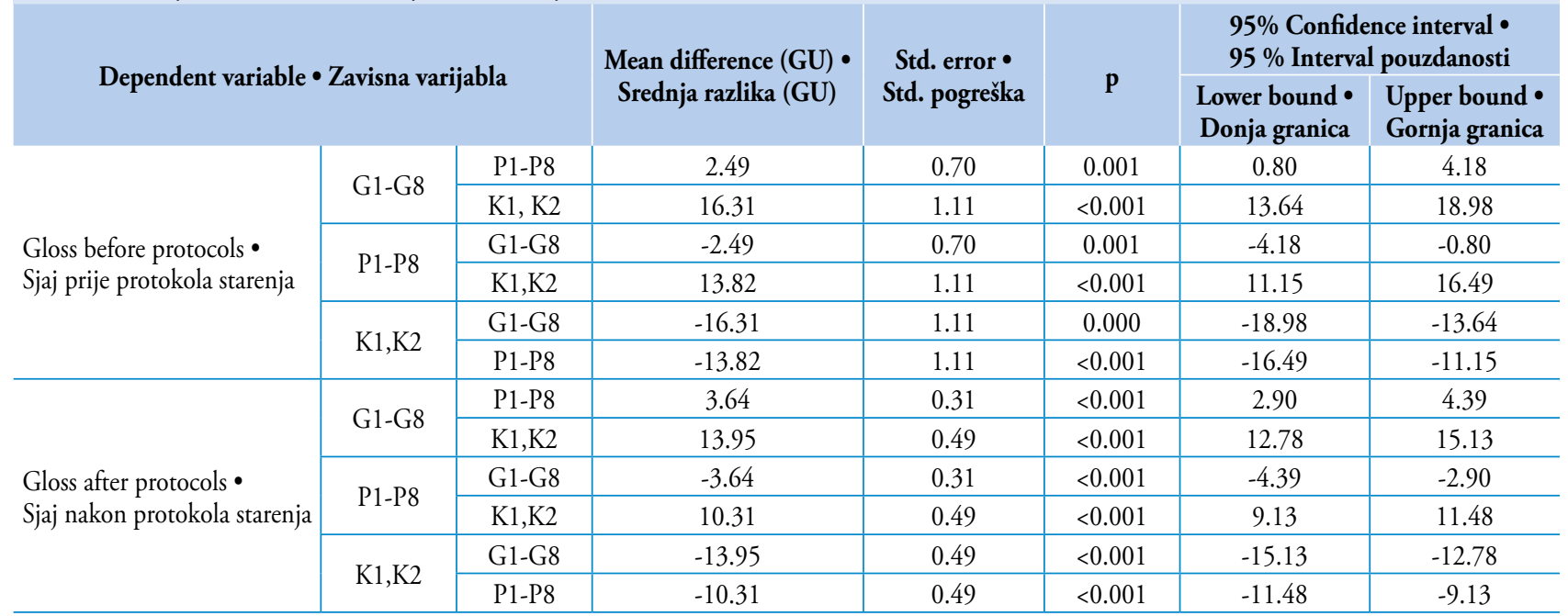

\begin{tabular}{|c|c|c|c|c|c|}
\hline $\begin{array}{c}\text { Specimens } \\
\text { Uzorci }\end{array}$ & $\begin{array}{c}\text { Before } A M \pm S D \\
(G U) \bullet \\
\text { Prije } A S \pm S D \\
(G U)\end{array}$ & Protocol $\bullet$ Protokol & $\begin{array}{c}\text { After } A M \pm S D \\
(G U) \bullet \\
\text { Poslije } A S \pm S D \\
(G U)\end{array}$ & $\begin{array}{c}\Delta \mathrm{G}_{\text {avg }}(\mathrm{GU}) \bullet \\
\Delta \mathrm{G}_{\text {sred }}(\mathrm{GU})\end{array}$ & $\mathbf{p}$ \\
\hline G1-G4 & $22.55 \pm 2.13$ & Hydrothermal degradation $\bullet$ Hidrotermalna degradacija & $19.49 \pm 1.36$ & -3.06 & $<0.001$ \\
\hline G5-G8 & $21.96 \pm 2.73$ & Chemical degradation $\bullet$ Kemijska degradacija & $17.58 \pm 3.27$ & -4.38 & $<0.001$ \\
\hline P1-P4 & $19.43 \pm 6.49$ & Hydrothermal degradation a Hidrotermalna degradacija & $14.78 \pm 1.87$ & -4.65 & $<0.001$ \\
\hline P5-P8 & $19.96 \pm 5.96$ & Chemical degradation $\bullet$ Kemijska degradacija & $14.99 \pm 1.66$ & -4.97 & $<0.001$ \\
\hline $\mathrm{K} 1, \mathrm{~K} 2$ & $5.95 \pm 0.41$ & Without degradation $\bullet$ Bez degradacije & $4.58 \pm 0.36$ & -1.37 & 0.263 \\
\hline
\end{tabular}

ference in the share of yttrium oxide $(10.90 \pm 0.30 \%)$ was somewhat larger than on the non-glazed side of glazed specimens $(11.85 \pm 0.00 \%)$. Non-glazed sides of glazed specimens had almost an identical share of chemical compounds as all other specimens.

Pre-aging recordings of specimens subjected to X-ray diffractometry (P1 and $\mathrm{P} 2$ ) show the diffraction maximum of tetragonal zirconia at a position of $30^{\circ} 2$ Theta and cubic phase peaks (Figure 2). Phase shares are expressed as percentages: tetragonal phase $62.7 \%$, and cubic phase $37.3 \%$. The phase composition analysis of specimens subjected to hydrothermal degradation in an autoclave (glazed G1, polished P1) (Fig. 3) revealed a full cubic-to-tetragonal phase transition. The phase composition of specimens subjected to chemical degradation in a corrosive medium (G5, P5) was virtually without change (Figure 4).

Pre-aging surface gloss measurements have manifested significantly higher gloss values (arithmetic mean $(\mathrm{AM})=$ $\left.22.26 \mathrm{GU}^{*}\right)$ in glazed specimens (G1-G8) than in polished specimens (P1-P8) $(\mathrm{AM}=19.77 \mathrm{GU} ; p<0.05)$. After aging protocols, a statistically significant reduction in gloss value
Snimka uzoraka (P1 i P2) na kojima je provedena difrakcijska analiza X-zrakama prije protokola starenja prikazuje difrakcijski maksimum tetragonskog cirkonijeva oksida s pozicijom oko $30^{\circ} 2$ Theta, te pikove kubične faze (slika 2.). Udjeli faza prikazani su u postotcima: tetragonske $62,7 \%$, kubične $37,3 \%$. Analize faznih sastava uzoraka izloženih hidrotermalnoj degradaciji u autoklavu (glazirani G1, polirani P1) (slika 3.) pokazuju da je kubična faza posve prešla u tetragonsku. Fazni sastav ostao je gotovo nepromijenjen na uzorcima izloženima kemijskoj degradaciji u korozivnom mediju (G5, P5) (slika 4.).

Mjerenja sjaja uzoraka prije protokola starenja pokazuju da glazirani uzorci (G1 - G8) imaju statistički značajno veću vrijednost sjaja površine [aritmetička sredina $(\mathrm{AS})=22,26$ $\mathrm{GU}^{*}$ ] od poliranih uzoraka (P1 - P8) (AS = 19,77 GU; $p<$ $0,05)$. Nakon protokola starenja dogodilo se statistički značajno smanjenje vrijednosti sjaja površine u objema skupinama uzoraka (glazirani AS = 18,54 GU; polirani AS $=14,89$ GU) (tablica 3.). Ovisno o vrsti provedenog protokola starenja, na glaziranim je uzorcima veća srednja promjena sjaja $(\Delta \mathrm{G})$ nastala u podskupini izloženoj kemijskoj degradaciji 
occurred in both specimen groups (glazed $\mathrm{AM}=18.54 \mathrm{GU}$; polished $\mathrm{AM}=14.89 \mathrm{GU}$ ). With regard to the aging protocols applied, gloss change $(\Delta \mathrm{G})$ was larger in the subgroup of glazed specimens subjected to chemical degradation (G5-G8) $\left(\Delta \mathrm{G}_{\mathrm{avg}}=-4.38 \mathrm{GU}\right)$ than in the subgroup subjected to hydrothermal degradation (G1-G4) $\left(\Delta \mathrm{G}_{\mathrm{avg}}=-3.08 \mathrm{GU}\right)$ (Table 4). In polished specimens, surface gloss reduction after both aging protocols was nearly identical (average gloss change after hydrothermal degradation (P1-P5): $\Delta \mathrm{G}_{\text {avg }}=-4.65 \mathrm{GU}$; after chemical degradation (P5-P8): $\Delta \mathrm{G}_{\text {avg }}=-4.97 \mathrm{GU}$ ) (Table 4). Control specimens displayed low gloss values from the beginning of the research as they received no surface treatment and their average gloss change $\Delta \mathrm{G}_{\text {avg }}=-1.37 \mathrm{GU}$ was not statistically significant.

The arithmetic means of roughness parameters $R_{a}$ and $R_{z}$ on polished specimens $\mathrm{P} 3$ and P6 obtained after experimental aging protocols were higher than the values obtained on
(G5 - G8): $\Delta \mathrm{G}_{\text {sred }}=-4,38 \mathrm{GU}$ u odnosu prema podskupini izloženoj hidrotermalnoj degradaciji $(\mathrm{G} 1-\mathrm{G} 4): \Delta \mathrm{G}_{\text {sred }}=$ $-3,08 \mathrm{GU}$ (tablica 4.). Na poliranim uzorcima nastupilo je podjednako smanjenje sjaja površine pri oba provedena protokola; hidrotermalna degradacija dovela je do srednje promjene sjaja (P1 - P4): $\Delta \mathrm{G}_{\text {sred }}=-4,65 \mathrm{GU}$, a kemijska degradacija rezultirala je srednjom promjenom sjaja (P5 - P8): $\Delta \mathrm{G}_{\text {sred }}=-4,97 \mathrm{GU}$ (tablica 4.). Kontrolni uzorci imaju nizak sjaj od početka istraživanja jer nisu površinski obrađivani, a srednja promjena sjaja $\Delta \mathrm{G}_{\text {sed }}=-1,37 \mathrm{GU}$ nije značajna.

Aritmetičke sredine parametara hrapavosti $R_{a}$ i $R_{z}$ na poliranim uzorcima P3 i P6 poslije eksperimentalnih protokola starenja nešto su viših vrijednosti u odnosu prema ostvarenim vrijednostima na istim uzorcima prije provedenog protokola starenja (tablica 5.).

Statistička analiza one-way-ANOVA testom (tablica 7.) pokazala je statistički značajno povećanje procijenjenih stan-

\begin{tabular}{|c|c|c|c|c|c|c|c|c|}
\hline \multirow{3}{*}{$\begin{array}{l}\text { Measurement No. } \\
\text { Mjerenje br. }\end{array}$} & \multicolumn{4}{|c|}{$\begin{array}{l}\text { Polished specimens before aging } \\
\text { Polirani uzorci prije starenja }\end{array}$} & \multicolumn{4}{|c|}{$\begin{array}{l}\text { Polished specimens after aging • } \\
\text { Polirani uzorci nakon starenja }\end{array}$} \\
\hline & \multicolumn{2}{|c|}{ Specimen P3 • Uzorak P3 } & \multicolumn{2}{|c|}{ Specimen P6 • Uzorak P6 } & \multicolumn{2}{|c|}{ Specimen P3 • Uzorak P3 } & \multicolumn{2}{|c|}{ Specimen P6 • Uzorak P6 } \\
\hline & $\begin{array}{l}\mathrm{Ra}, \\
\mu \mathrm{m}\end{array}$ & $\begin{array}{l}\mathrm{Rz}, \\
\mu \mathrm{m}\end{array}$ & $\begin{array}{l}\mathrm{Ra}, \\
\mu \mathrm{m}\end{array}$ & $\begin{array}{l}\mathrm{Rz}, \\
\mu \mathrm{m}\end{array}$ & $\begin{array}{l}\mathrm{Ra}, \\
\mu \mathrm{m}\end{array}$ & $\begin{array}{l}\mathrm{Rz}, \\
\mu \mathrm{m}\end{array}$ & $\begin{array}{l}\mathrm{Ra}, \\
\mu \mathrm{m}\end{array}$ & $\begin{array}{l}\mathrm{Rz} \\
\mu \mathrm{m}\end{array}$ \\
\hline 1 & 0.73 & 4.5 & 0.52 & 3.26 & 0.71 & 4.39 & 0.7 & 4.48 \\
\hline 2 & 0.56 & 3.77 & 0.55 & 3.64 & 0.65 & 4.45 & 0.66 & 4.16 \\
\hline 3 & 0.71 & 4.19 & 0.53 & 3.67 & 0.58 & 3.9 & 0.68 & 4.32 \\
\hline 4 & 0.7 & 4.11 & 0.56 & 3.68 & 0.62 & 4.32 & 0.63 & 3.96 \\
\hline 5 & 0.62 & 3.83 & 0.54 & 3.5 & 0.69 & 4.47 & 0.64 & 3.65 \\
\hline 6 & 0.61 & 3.86 & 0.58 & 3.66 & 0.63 & 3.89 & 0.58 & 3.91 \\
\hline 7 & 0.67 & 3.84 & 0.6 & 3.78 & 0.63 & 4.2 & 0.64 & 3.75 \\
\hline 8 & 0.57 & 3.22 & 0.57 & 3.41 & 0.72 & 4.4 & 0.63 & 3.93 \\
\hline 9 & 0.69 & 4.45 & 0.65 & 4.16 & 0.66 & 4.28 & 0.55 & 3.84 \\
\hline 10 & 0.67 & 4.52 & 0.54 & 3.7 & 0.69 & 4.75 & 0.59 & 3.41 \\
\hline$\overline{R a}, \overline{R z}$ & 0.65 & 4.03 & 0.56 & 3.65 & 0.66 & 4.31 & 0.63 & 3.94 \\
\hline$s, \mathrm{~nm}$ & 59 & 408 & 39 & 239 & 44 & 260 & 46 & 316 \\
\hline
\end{tabular}

Table 6 Values of parameters $R_{a}$ and $R_{z}$ on glazed specimens (G3 and $\mathrm{G} 6$ ) before and after aging protocols.

Tablica 6. Vrijednosti parametara hrapavosti $R_{a}$ i $R_{z}$ glaziranih uzoraka (G3 i G6) prije i poslije protokola starenja

\begin{tabular}{|c|c|c|c|c|c|c|c|c|}
\hline \multirow{3}{*}{$\begin{array}{l}\text { Measurement No. } \\
\text { Mjerenje br. }\end{array}$} & \multicolumn{4}{|c|}{$\begin{array}{l}\text { Glazed specimens before aging • } \\
\text { Glazirani uzorci prije starenja }\end{array}$} & \multicolumn{4}{|c|}{$\begin{array}{l}\text { Glazed specimens after aging } \\
\text { Glazirani uzorci nakon starenja }\end{array}$} \\
\hline & \multicolumn{2}{|c|}{ Specimen G3 • Uzorak G3 } & \multicolumn{2}{|c|}{ Specimen G6 • Uzorak G6 } & \multicolumn{2}{|c|}{ Specimen G3 • Uzorak G3 } & \multicolumn{2}{|c|}{ Specimen G6 • Uzorak G6 } \\
\hline & $\begin{array}{l}\mathrm{Ra} \\
\mu \mathrm{m}\end{array}$ & $\begin{array}{l}\mathrm{Rz}, \\
\mu \mathrm{m}\end{array}$ & $\begin{array}{l}\mathrm{Ra}, \\
\mu \mathrm{m}\end{array}$ & $\begin{array}{l}\mathrm{Rz}, \\
\mu \mathrm{m}\end{array}$ & $\begin{array}{l}\mathrm{Ra}, \\
\mu \mathrm{m}\end{array}$ & $\begin{array}{l}\mathrm{Rz}, \\
\mu \mathrm{m}\end{array}$ & $\begin{array}{l}\mathrm{Ra} \\
\mu \mathrm{m}\end{array}$ & $\begin{array}{l}\mathrm{Rz} \\
\mu \mathrm{m}\end{array}$ \\
\hline 1 & 1.05 & 3.72 & 1.01 & 3.35 & 0.52 & 1.83 & 1.71 & 5.61 \\
\hline 2 & 0.64 & 2.43 & 1.16 & 3.18 & 0.47 & 1.79 & 1.24 & 3.44 \\
\hline 3 & 0.92 & 3.8 & 1.16 & 3.93 & 0.53 & 2.07 & 1.35 & 3.9 \\
\hline 4 & 0.78 & 2.67 & 0.76 & 2.87 & 0.71 & 4.27 & 1.13 & 3.5 \\
\hline 5 & 0.82 & 2.94 & 0.79 & 2.72 & 0.7 & 2.54 & 1.06 & 3.41 \\
\hline 6 & 0.95 & 3.76 & 0.83 & 3.33 & 0.64 & 2.98 & 0.86 & 3.11 \\
\hline 7 & 1.22 & 4.89 & 0.89 & 3.03 & 0.88 & 3.28 & 1.22 & 3.64 \\
\hline 8 & 0.68 & 2.31 & 0.89 & 2.92 & 0.66 & 2.66 & 1.38 & 4.74 \\
\hline 9 & 0.86 & 2.49 & 0.97 & 3.12 & 0.76 & 3.23 & 1.42 & 4.44 \\
\hline 10 & 0.64 & 2.24 & 0.82 & 3.19 & 0.89 & 2.93 & 1.26 & 4.46 \\
\hline$\overline{R a}, \overline{R z}$ & 0.86 & 3.13 & 0.93 & 3.16 & 0.68 & 2.76 & 1.26 & 4.03 \\
\hline$s, \mathrm{~nm}$ & 187 & 876 & 144 & 335 & 144 & 759 & 228 & 773 \\
\hline
\end{tabular}


Table 7 Statistical analysis of roughness parameters $R_{a}$ and $R z_{z}$ before and after aging protocols on $\mathrm{G} 3, \mathrm{G} 6, \mathrm{P} 3$ and P6 specimens. (One-wayANOVA, $p<0,05)$.

Tablica 7. Statistička analiza vrijednosti parametara hrapavosti $R_{a}$ i $R_{z}$ prije i poslije protokola starenja na uzorcima G3, G6, P3 i P6. (one-wayANOVA, $p<0,05)$

\begin{tabular}{|c|c|c|c|c|c|c|c|}
\hline $\begin{array}{c}\text { Specimen • } \\
\text { Uzorak }\end{array}$ & $\begin{array}{c}\text { Protocol • } \\
\text { Protokol }\end{array}$ & $\begin{array}{c}\mathrm{Ra} \\
\mathrm{AM} \pm \mathrm{SD} \text { before } \\
\mathrm{Ra} \\
\mathrm{AS} \pm \mathrm{SD} \text { prije }\end{array}$ & $\begin{array}{c}\mathrm{Ra} \\
\mathrm{AM} \pm \mathrm{SD} \text { after } \\
\mathrm{Ra} \\
\mathrm{AS} \pm \mathrm{SD} \text { poslije }\end{array}$ & $\mathbf{p}$ & $\begin{array}{c}\mathrm{Rz} \\
\mathrm{AM} \pm \mathrm{SD} \text { before } \\
\mathrm{Rz} \\
\mathrm{AS} \pm \mathrm{SD} \text { prije }\end{array}$ & $\begin{array}{c}\mathrm{Rz} \\
\mathrm{AM} \pm \mathrm{SD} \text { after } \bullet \\
\mathrm{Rz} \\
\mathrm{AS} \pm \mathrm{SD} \text { poslije }\end{array}$ & $\mathbf{p}$ \\
\hline G3 & $\mathrm{HD}$ & $0.86 \pm 0.035$ & $0.68 \pm 0.02$ & 0.03 & $3.13 \pm 0.77$ & $2.76 \pm 0.58$ & 0.33 \\
\hline G6 & $\mathrm{CD} \bullet \mathrm{KD}$ & $0.93 \pm 0.02$ & $1.26 \pm 0.05$ & 0.001 & $3.16 \pm 0.11$ & $4.03 \pm 0.06$ & 0.005 \\
\hline P3 & HD & $0.65 \pm 0.004$ & $0.66 \pm 0.002$ & 0.834 & $4.03 \pm 0.166$ & $4.31 \pm 0.07$ & 0.09 \\
\hline P6 & $\mathrm{CD} \bullet \mathrm{KD}$ & $0.56 \pm 0.001$ & $0.63 \pm 0.002$ & 0.003 & $3.65 \pm 0.06$ & $3.94 \pm 0.1$ & 0.03 \\
\hline
\end{tabular}

the same specimens before aging protocols were performed (Table 5).

The results of one-way ANOVA point to a statistically significant increase in the values of estimated standard deviations for roughness parameters $R_{a}$ and $R_{z}$ on polished specimen P6 (Table 7).

The arithmetic means of roughness parameters $R_{a}$ and $R_{z}$ on glazed specimen G3 obtained after the aging protocol were lower than before the aging protocol was performed. An increase in the values of roughness parameters $R_{a}$ and $R_{z}$ after the aging treatment was present on glazed specimen $\mathrm{G} 6$ (Table 6).

The results of one-way ANOVA point to a statistically significant change in the values of estimated standard deviations for roughness parameter $R$ on glazed specimens G3 (decrease) and G6 (increase) as well as for roughness parameter $R_{z}$ on glazed specimen G6 (increase) (Table 7).

\section{Discussion}

Various aging protocols provide an insight into the possible behavior of the constituent material in the mouth over a lengthy period of time. This research comprised several contemporary and costly protocols. A three-hour period was chosen for exploring hydrothermal degradation in an autoclave because it corresponded to a restoration usage period of 10-15 years (29-31), which should be the expected restoration usage period both from a therapist's and a patient's point of view. Submersing specimens into a medium of low $\mathrm{pH}$ value $\left(\mathrm{pH}\right.$ 2.49) at a temperature of $80{ }^{\circ} \mathrm{C}$ for 16 hours (ISO 6872) is a method of examining the stability of materials under the conditions similar to those in the oral cavity, with constantly changing temperature and $\mathrm{pH}$ values (3032). Plaque that clings to the surface of dental hard tissue and dentures has a $\mathrm{pH}$ value in its depth similar to the $\mathrm{pH}$ value of the acid utilized in this research; hence the effect of plaque was simulated in the present study, as well (33). The quantity of specimens in this research was defined after a pilot study, in agreement with associates/experts under whose supervision the tests were administered. The tested number of specimens sufficed for a part of the testing (EDXRF, XRD, surface roughness) because the materials had been manufactured in a controlled environment. Furthermore, these testing methods were employed using very expensive, sophisticated apparatuses and methods which would have obtained the results relevant even on a small number of specimens. It is to be ex- dardnih odstupanja parametara hrapavosti $R_{a}$ i $R_{z}$ na uzorku P6.

Ostvarene aritmetičke sredine rezultata mjerenja parametara hrapavosti $R$ i $R$ na glaziranom uzorku G3 bilježe niže vrijednosti nakon protokola starenja. Na glaziranom uzorku G6 uočen je porast vrijednosti parametara hrapavosti $R_{a}$ i $R_{z}$ nakon protokola starenja (tablica 6.).

Statistička analiza one-way-ANOVA testom (tablica 7.) pokazala je statistički značajno smanjenje procijenjenih standardnih odstupanja parametra hrapavosti $R_{a}$ na glaziranom uzorku G3 te statistički značajno povećanje procijenjenih standardnih odstupanja parametara hrapavosti $R_{a}$ i $R_{z}$ na glaziranom uzorku G6.

\section{Rasprava}

Različiti protokoli starenja daju uvid u moguće ponašanje gradivnog materijala u ustima tijekom duljeg razdoblja. Ovo istraživanje obuhvatilo je više suvremenih i skupih protokola. Za ispitivanje hidrotermalne degradacije u autoklavu odabrano je vrijeme od 3 sata, što odgovara razdoblju od 10 do 15 godina korištenja nadomjeska u ustima $(29-31)$. To bi trebalo biti očekivano razdoblje primjene nadomjestka za terapeuta i pacijenta. Uranjanje uzoraka u medij niske $\mathrm{pH}$ vrijednosti $(\mathrm{pH} 2,49)$ na temperaturi od $80{ }^{\circ} \mathrm{C}$ tijekom 16 sati (ISO 6872), način je ispitivanja kemijske postojanosti materijala u uvjetima konstantnih promjena $\mathrm{pH}$ vrijednosti i temperature kakva je u usnoj šupljini $(30$ - 32). Plak koji adherira na površine tvrdih zubnih tkiva, pa tako i nadomjestaka, u svojoj dubini ima $\mathrm{pH}$ vrijednost vrlo sličnu $\mathrm{pH}$ vrijednosti korištene kiseline u ovom istraživanju, čime se i taj utjecaj simulira (33). Broj uzoraka za ovo istraživanje definiran je nakon pilot-studije u dogovoru sa suradnicima/stručnjacima pod čijim su nadzorom provedena testiranja. Za dio testiranja (EDXRF, XRD, površinska hrapavost) bio je dovoljan testirani broj uzoraka jer je riječ o materijalu proizvedenom u kontroliranim uvjetima. Osim toga, korištene metode testiranja provedene su na vrlo skupim i sofisticiranim uređajima postupcima čiji su rezultati testiranja relevantni i na malom broju uzoraka. Može se očekivati da će mali broj uzoraka biti reprezentativan za određenu vrstu testiranja te da će dobiveni rezultati biti ponovljivi i primjenjivi na većem broju uzoraka. Za neka testiranja (XRD, površinska hrapavost) svakako bi bilo poželjno imati više uzoraka, ali potrebno je uzeti u obzir iznimno visoku cijenu testiranog materijala, vrlo skupu 
pected that a small quantity of specimens would be representative of a certain test type and that the obtained results could be repeated and applied to a greater number of specimens. It would have certainly been desirable to have more specimens for other tests (XRD, surface roughness), but one ought to take into account the extremely high price of the tested material, great costs for specimen manufacture as well as the cost and delicacy of measuring instruments.

At room temperature, pure zirconia exists in the monoclinic phase and great tension inside the material renders it unusable in the field of dental medicine, i.e. fixed prosthodontics (14). Yttrium oxide is the most frequently used stabilizer in zirconia ceramics $(8-12,14)$. When its share is $3-8 \%$, it is possible to stabilize the tetragonal phase of zirconia ceramics, the result being so-called Y-TZP (yttrium-stabilized tetragonal zirconia polycrystal material). In the present study, the post-aging share of yttrium oxide (polished specimens $11.88 \pm 0.07 \%$, control specimens $11.75 \pm 0.01 \%$, glazed specimens $10.90 \pm 0.30 \%-11.85 \pm 0.00 \%)$ was not significantly lower than the pre-aging share $(11.97 \pm 0.13 \%)$, i.e. the chemical composition of the specimens was not significantly altered (Table 2). A somewhat lower share of yttrium oxide on the glazed side of glazed specimens $(10.90 \pm$ $0.30 \%$ ) can be explained by the presence of strontium and zinc in the glaze. Tested specimens manifested the stability of their chemical composition after being subjected to both hydrothermal degradation in an autoclave and chemical degradation in acetic acid. So far, there has been no mechanism for which one could say with certainty that it ages zirconia, although there have been some theories that could account for that phenomenon. A theory by Lange et al., based on an analysis of SEM images, suggests that water reacts with $\mathrm{Y}_{2} \mathrm{O}_{3}$, creating yttrium hydroxide $\left(\mathrm{Y}(\mathrm{OH})_{3}\right)$, a chemical compound that prompts the loss of stabilizers in the surrounding grains and a tetragonal-to-monoclinic transformation (34). According to Yoshimura, water evaporation causes the bond between zirconium and oxygen in zirconia ceramics to break; the newly-free - $\mathrm{OH}$ ions exert stress and strain on the material and the outcome is a tetragonal-to-monoclinic transformation (35). Chevalier et al. believe that free oxygen radicals $\mathrm{O}^{2-}$, formed as a consequence of water dissociation, destabilize the structure of Y-TZP and trigger LTD (36). It has been proven that a tetragonal-to-monoclinic transformation starts on the surface of the material and progresses into its interior (8-14). This transformation leads to an increase in the volume of surface grains, which rise above the rest of the surface, create micro-cracks and open up the way for water and thereby the transformation to penetrate deeper into the material. Under the strain of e.g. masticatory force in the mouth, a restoration will ultimately crack (37-39). A greater post-aging share of stabilizing yttrium oxide calculated in this study (up to $12 \%$ ) suffices for maintaining the stability of the crystal structure of specimens (15-17), i.e. for preventing a phase transformation. The first hypothesis is thus confirmed.

At the start of the present study, two phases were found to co-exist in specimens: tetragonal (approx. 63\%) and cubic (approx. 37\%). After being exposed to hydrothermal degradation in an autoclave, the crystal structure of the specimens izradu uzoraka te skupoću i osjetljivost uređaja na kojima su mjerenja obavljena.

Čisti cirkonij je pri sobnoj temperaturi u monoklinskoj fazi, pa je neupotrebljiv u području dentalne medicine, odnosno fiksne protetike, zbog velike napetosti unutar materijala (14). Itrijev oksid najčešće je korišteni stabilizator u cirkonijoksidnoj keramici $(8-12,14)$. U udjelu od 3 do $8 \%$ moguće je stabilizirati tetragonsku fazu cirkonij-oksidne keramike pri sobnoj temperaturi i dobiti tzv. Y-TZP (itrijem stabilizirani cirkonijev dioksid). U ovom istraživanju nije se dogodila značajna redukcija molekula itrijeva oksida nakon obaju protokola starenja (11,88 $\pm 0,07 \%$ za polirane uzorke, $11,75 \pm$ $0,01 \%$ za kontrolne uzorke, $10,90 \pm 0,30 \%-11,85 \pm 0,00$ $\%$ za glazirane uzorke) u odnosu prema mjerenjima prije starenja $(11,97 \pm 0,13 \%)$, odnosno nije se dogodila značajna promjena kemijskog sastava uzoraka (tablica 2). Nešto niže vrijednosti udjela itrijeva oksida izmjerene su na glaziranoj strani glaziranih uzoraka $(10,90 \pm 0,30 \%)$, što se objašnjava prisutnošću stroncija i cinka iz glazure. Testirani uzorci pokazali su stabilnost kemijskog sastava nakon izlaganja hidrotermalnoj degradaciji u autoklavu i nakon kemijske degradacije u octenoj kiselini. Dosad nije opisan ni jedan mehanizam za koji bi se sa sigurnošću moglo reći da dovodi do starenja cirkonijeva oksida, no postoje odredene teorije kojima bi se to moglo objasniti. Lange i suradnici su, analizirajući snimke dobivene SEM-om, predložili teoriju u kojoj voda reagira $s \mathrm{Y}_{2} \mathrm{O}_{3}$ tvoreći spojeve itrijeva hidroksida $\left(\mathrm{Y}(\mathrm{OH})_{3}\right)$ koji dovode do gubitka stabilizatora u okolnim zrnima cirkonijeva dioksida koji se zatim transformiraju iz tetragonske u monoklinsku fazu (34). Prema Yoshimuri, isparavanje vode utječe na vezu cirkonija i kisika u cirkonij-oksidnoj keramici tako što dovodi do loma te veze i nastanka slobodnih $-\mathrm{OH}$ iona koji stvaraju naprezanja i napetost u materijalu te posljedično tetragonsko-monoklinsku (t-m) transformaciju (35). Chevalier i suradnici mišljenja su da slobodni kisikovi radikali $\mathrm{O}^{2}$ koji nastaju disocijacijom vode destabiliziraju strukturu YTZP te nastaje LTD (36). Dokazano je da t-m transformacija počinje na površini materijala i progredira u unutrašnjost (8 - 14). Transformacijom površinskih zrna povećava se njihov volumen te se zrna izdižu iznad preostale površine materijala i stvaraju mikropukotine, čime se otvaraju putovi penetraciji vode dublje u materijal propagirajući transformaciju sve dublje u unutrašnjost materijala $(8-14)$. To će u konačnici, pod opterećenjem, kao što su npr. žvačne sile u ustima, završiti lomom nadomjestka (37 - 39). U ovom istraživanju ustanovljen je veći udio itrijeva oksida (do $12 \%$ ukupnog udjela elemenata/spojeva) nakon provedenih protokola starenja, čime je udio stabilizatora dovoljan za održavanje stabilne kristalne strukture uzoraka (15 - 17), odnosno sprječavanja fazne transformacije. Time se potvrduje prva hipoteza.

Uzorci su na početku ovog istraživanja pokazali postojanje dviju faza: tetragonske (oko $63 \%$ ) i kubične (oko $37 \%$ ). Nakon izlaganja uzoraka hidrotermalnoj degradaciji u autoklavu, kristalna struktura se promijenila o prešla u posve tetragonsku strukturu (100\%). Za razliku od prog protokola starenja, pri korozijskoj degradaciji nije ustanovljena promjena kristalne strukture u uzorcima, odnosno koegzistirale su tetragonska i kubična struktura u gotovo identičnom postot- 
fully transitioned to a tetragonal structure (100\%). Unlike the first aging protocol, degradation in a corrosive medium did not bring about a change in the crystal structure of the specimens, i.e. tetragonal and cubic structures continued to co-exist in nearly the same ratio as at the start of the research. These analyses did not establish a phase (tetragonal-to-monoclinic) transformation of monolithic zirconia specimens; therefore the second hypothesis is accepted. A monoclinic phase in monolithic zirconia with a mixed tetragonal-cubic microstructure was not manifested in a study by Muñoz et al., although the share of the cubic phase increased after hydrothermal degradation (39). Kolakarnprasert et al. did not prove the manifestation of a monoclinic phase in the material after exposing specimens submerged in water to a temperature of $120^{\circ} \mathrm{C}$ for a twelve-hour period; their findings correspond to the results of this study (15).

Long-term stability, smoothness and gloss of a restoration are important from a hygienic $(20-23,28)$, tribological $(20,21,23)$ and esthetic point of view $(19,22,40)$. Surface roughness and final surface treatment on FPD affect the color stability of dental materials (40). Discoloration of dentures, caused by beverages such as coffee and tea, has been described in literature (41). In the present study, zirconia ceramic was subjected to two types of final surface treatment - polishing and glazing. Glazing is a standard surface finishing treatment which closes any pores left after sintering, allows for a better aesthetic impression of the restoration and reduces the accumulation of biofilm (42). In this research, surface state was expressed in terms of two parameters - surface gloss and surface roughness. In the imitation of a natural tooth in fixed prosthodontic therapy, a lot of emphasis is placed on the successful reproduction of surface texture (22). An enamel-like texture is attained by manually spreading a thin layer of glaze over a finished restoration (22). Because of divergences in the refraction of light, differences in texture generate differences in color perception. In this study, both experimental protocols brought about a statistically significant reduction of surface gloss in both specimen groups (G1-G8, P1-P8), which prompts the acceptance of the third hypothesis $(p<0.05)$. From the beginning, glazed specimens manifested significantly higher surface gloss values than polished specimens. This study established that the surface gloss of specimens was reduced regardless of the final surface treatment applied, with both subgroups of polished specimens (P1-P4, P5-P8) having a higher mean gloss change $\Delta \mathrm{G}$ than glazed specimens (G1-G4, G5-G8). It needs to be noted that surface gloss reduction in an oral cavity would unfold at a slower pace than during experimental protocols. Control specimens (K1, K2) did not manifest significant surface gloss reduction in this research, although their gloss values were low from the onset because they were not subjected to any surface treatment. Gloss reduction in glazed specimens is most likely a result of congruent dissolution of glaze during experimental protocols, especially during chemical degradation in a corrosive medium, which is confirmed by the results relating to surface roughness. A glazed specimen subjected to aging in an autoclave (G3) recorded a decrease of parameters $R(p=0.03)$ and $R_{z}(p=0.33)$, while a specimen submerged in a corrosive medi- ku kao na početku istraživanja. Ovim analizama nije utvrđena fazna $(\mathrm{t}-\mathrm{m})$ transformacija u uzorcima monolitne cirkonij-oksidne keramike, čime je prihvaćena druga hipoteza. Muñoz i suradnici u monolitnom cirkonijevu oksidu tetragonsko-kubične mikrostrukture također nisu dokazali pojavu monoklinske faze, ali se u njihovoj studiji, pri hidrotermalnoj degradaciji, pojavio veći udjel kubične u odnosu prema tetragonskoj fazi (39). Kolakarnprasert i suradnici, pri izlaganju uzoraka temperaturi od $120^{\circ} \mathrm{C}$ tijekom 12 sati u vodi, također nisu dokazali prisutnost monoklinske faze u materijalu, što je u skladu s rezultatima ove studije (15).

Površina nadomjestka koja je dugoročno stabilna, glatka i sjajna važna je s higijenskog $(20-23,28)$, tribološkog $(20,21,23)$ i estetskog aspekta $(19,22,40)$. Hrapavost površine i načini završne obrade površine nadomjestka utječu na stabilnost boje dentalnih materijala (40). U literaturi su opisane diskoloracije nadomjestaka pićima poput kave i čaja (41). U ovom istraživanju površina cirkonij-oksidne keramike završno je obrađena na dva načina - poliranjem ili glaziranjem. Glaziranje je standardni način završavanja keramičke restauracije kojim se zatvaraju pore koje su eventualno zaostale nakon procesa sinteriranja, omogućujući bolji estetski dojam nadomjestka, ali i reducirajući akumulaciju biofilma (42). Stanje površine u ovom istraživanju prikazano je dvama mjerenim parametrima - sjajem i hrapavošću površine. Pri oponašanju izgleda prirodnog zuba u fiksnoprotetičkoj terapiji, velik naglasak se stavlja na uspješnu reprodukciju površinske teksture (22). Tekstura nalik na zubnu caklinu postiže se ručnim nanošenjem tankog sloja glazure na gotovi nadomjestak (22). Zbog različitog loma svjetlosti razlike u teksturi izazivaju različitu percepciju boje. U ovom istraživanju statistički značajno smanjenje sjaja površine nastalo je tijekom obaju eksperimentalnih protokola u obje skupine uzoraka (G1 - G8, P1 - P8) u odnosu prema početnim mjerenjima, što dovodi do prihvaćanja treće hipoteze $(p<0,05)$. Glazirani uzorci su već na početku istraživanja imali statistički značajno veću vrijednost sjaja površine od poliranih. U ovom istraživanju dokazano je smanjenje sjaja površine uzoraka bez obzira na način završne obrade, $s$ tim da je veća srednja promjena sjaja $\Delta \mathrm{G}$ nastupila u objema podskupinama poliranih uzoraka (P1 - P4, P5 - P8) u odnosu prema glaziranim uzorcima (G1 - G4, G5 - G8). Važno je istaknuti da bi proces smanjenja sjaja površine nadomjestka u usnoj šupljini bio mnogo sporiji u odnosu prema eksperimentalnim protokolima. Kontrolni uzorci u ovom istraživanju također pokazuju smanjenje sjaja površine koje nije statistički značajno, iako je sjaj površine nizak od početka jer nisu završno obrađivani. Smanjenje sjaja glaziranih uzoraka (G1 - 4, G5 - G8) vjerojatno je rezultat kongruentnog otapanja sloja glazure pri eksperimentalnim protokolima, osobito pri kemijskoj degradaciji u korozivnom mediju, što potvrđuju rezultati površinske hrapavosti. Na glaziranom uzorku podvrgnutom postupku starenja u autoklavu (G3) zabilježeno je smanjenje vrijednosti parametra $R$ koje je značajno $(p=0,03)$ i parametra $R_{z}$ koje nije značajno ( $p=0,33)$, a na uzorku uronjenom u korozivni medij (G6) uočeno je značajno povećanje parametara hrapavosti $R_{a}$ i $R_{z}(p<0,05)$. Glazura kao amorfni materijal nije otporna na agresivne vanjske utjecaje niti je kemijski stabilna, odno- 
um (G6) recorded a significant increase in roughness parameters $R_{a}$ and $R_{z}(p<0.05)$. As an amorphous material, glaze is not resistant to aggressive external influences nor is it chemically stable/inert. In an aggressive medium, surface ions perish from glaze, some irregularities appear on the surface and roughness is increased, which is in agreement with findings of Manicone et al. (1) and Milleding et al. (43, 44). The reduction of roughness parameters $R_{a}$ and $R_{z}$ in a glazed specimen aged in an autoclave (Table 6) supports the finding that aging a specimen in an autoclave "smoothed" its surface, therefore mean gloss change $\Delta \mathrm{G}$ in those specimens (G1-G4) was lower than in polished specimens (P1-P4). The effect of hydrothermal degradation in an autoclave on glazed specimens (G1-G4) was reduced by a protective coating on the surface (glaze) so that the penetration of water and degradation of base material were inhibited, unlike in specimens without a protective coating. This was confirmed by Palla et al., who proved that water infiltrates through the surface of a nonglazed glass ceramic restoration, which results in the disintegration of the material's structure (45). Camposilvan et al. have suggested spreading glaze on all zirconia restorations so as to inhibit the impact of a hydrothermal aging protocol on the surface of the material (46). In polished specimens (P1P8), surface gloss decreased and gloss change $\Delta \mathrm{G}$ was higher than in glazed specimens (G1-G8), which could be attributed to an increase in the values of measured roughness parameters during both experimental protocols (Tables 5 and 7). Štefančić confirmed these findings in her doctoral dissertation (47). An increase in roughness was not substantial in a specimen subjected to hydrothermal degradation (P3), when compared to a specimen subjected to chemical degradation (P6), but it undoubtedly had an impact on surface gloss reduction in all polished specimens (47). Judging by the results relating to roughness parameters, the fourth hypothesis can be partially accepted because a significant change in roughness occurred in specimens G6 and P6, which belong to subgroups of glazed and polished specimens respectively, which were subjected to chemical degradation in a corrosive medium $(p<0.05)$. Surface roughness of control specimens was not measured using profilometry since these specimens had not been subjected to any type of final surface treatment and their surface roughness was high; hence it serves no purpose to compare it to the roughness of either polished or glazed specimens.

Relevant literature points to the conclusion that all types of dental ceramics (silica-based and oxide-based) exhibit reactivity in an aqueous medium, thus a completely inert ceramic material does not exist $(1,43,44,47)$. Polycrystalline, oxidebased ceramics also release ions, but to a much lesser extent than silica-based ceramics $(43,44,47)$.

\section{Conclusions}

Within the limitations of this study, it can be concluded that experimental aging protocols do not reduce the share of stabilizing yttrium oxide and consequently do not generate a tetragonal-to-monoclinic phase transformation, i.e. aging of translucent multilayer zirconia ceramic. sno inertna. Iz glazure u agresivnom mediju gube se površinski ioni, čime se stvaraju površinske nepravilnosti koje povećavaju hrapavost, što je u skladu s istraživanjima Maniconea i suradnika (1) te Milledinga i suradnika $(43,44)$. Smanjenje parametara hrapavosti $R_{a}$ i $R_{z}$ nastalo na glaziranom uzorku koji je stario u autoklavu (tablica 6.), govori u prilog da je proces starenja u autoklavu rezultirao zagladivanjem površine uzoraka, zbog čega je i srednja promjena sjaja $\Delta \mathrm{G}$ kod tih uzoraka (G1 - G4) manja u odnosu prema poliranim uzorcima (P1 - P4). Utjecaj hidrotermalne degradacije u autoklavu kod glaziranih uzoraka (G1 - G4) smanjen je zbog zaštitne prevlake na površini (glazure), čime se bilo kakva penetracija vode u materijal, odnosno degradacija osnovnog materijala neće događati, za razliku od uzoraka koji nemaju zaštitnu prevlaku. Tu tvrdnju potvrđuju Palla i suradnici koji su dokazali da se kroz površinu neglaziranoga staklokeramičkog nadomjestka u materijal infiltrira voda, što rezultira dezintegracijom strukture (45). Camposilvan i suradnici sugeriraju nanošenje glazure na sve nadomjestke cirkonij-oksidne keramike kako bi se spriječio utjecaj hidrotermalnoga protokola starenja na površinu materijala (46). Na poliranim uzorcima (P1 - P8) utvrđeno je smanjenje sjaja površine uz veću promjenu sjaja $\Delta \mathrm{G}$ u odnosu prema glaziranim uzorcima (G1G8), što bi se moglo pripisati povećanju vrijednosti mjerenih parametara hrapavosti pri oba eksperimentalna protokola (tablice 5. i 7.). Štefančić u svojoj disertaciji također potvrđuje te navode (47). Povećanje hrapavosti nije značajno za uzorak izložen hidrotermalnoj degradaciji (P3) u odnosu prema uzorku izloženom kemijskoj degradaciji (P6), ali je zasigurno utjecalo na opće smanjenje sjaja površine poliranih uzoraka (47). Na temelju rezultata parametara hrapavosti može se govoriti o djelomičnom prihvaćanju četvrte hipoteze jer je značajna promjena hrapavosti površine nastala na uzorcima G6 i P6 koji pripadaju podskupinama glaziranih i poliranih uzoraka izloženih kemijskoj degradaciji u korozivnom mediju $(p<$ $0,05)$. Na kontrolnim uzorcima nije provedeno mjerenje hrapavosti površine profilometrijom jer nisu površinski obrađivani ni jednom metodom, čime je hrapavost površine velika i nema svrhe raditi usporedbu s hrapavošću površine poliranih, odnosno glaziranih uzoraka.

Pregledom relevantne literature može se zaključiti da sve vrste zubnih keramika (silikatne i oksidne) pokazuju kemijsku reaktivnost u vodenome mediju tako da ne postoji posve inertan keramički materijal $(1,43,44,47)$. Polikristalinične, oksidne keramike, za razliku od onih silikatnih, također otpuštaju ione, ali u mnogo manjoj količini $(43,44,47)$.

\section{Zaključak}

Unatoč ograničenjima ove studije može se zaključiti da eksperimentalni protokoli starenja ne rezultiraju redukcijom udjela stabilizatora itrijeva oksida, što posljedično ne dovodi do tetragonsko-monoklinsko fazne transformacije, odnosno do starenja translucentne multilayered cirkonij-oksidne keramike.

Eksperimentalni protokoli starenja dovode do značajnog smanjenja sjaja površine svih uzoraka, bez obzira na način po- 
Regardless of the surface treatment applied, surface gloss on all specimens was significantly reduced by experimental aging protocols, with surface gloss reduction being somewhat greater in polished specimens. The reduction of the gloss of specimens is an indicator of possible repercussions on the esthetic properties of dentures, particularly in polished specimens.

In contrast to the changes in the value of roughness parameters in glazed specimens subjected to aging in an autoclave (decrease) and glazed specimens submerged in a corrosive medium (increase), a significant increase in the value of roughness parameters in polished specimens following both aging protocols is a signal of substantial unwanted changes in surface state caused by polishing.

Glazing will have better esthetic, hygienic and tribological effects on the surface of a FPD than polishing.

\section{Conflict of interests}

The authors report no conflict of interests.

\section{Acknowledgements}

Science project: Defining the Possibility of Using Mini Dental Implants: the results in "in vitro" and in clinical prospective studies. (No 1218) Funded by Croatian Science Foundation, by Professor Asja Čelebić, DMD, MSc, PhD

\section{Author's contribution}

K.M. - designed the research as a part of her doctoral thesis, conducted all experimental phases of the research, wrote the article; I.M. - assisted in gloss measurements and the interpretation of the results in that experimental part of the research; J.O. - assisted in the analysis of the specimens' chemical composition and the interpretation of the results in that experimental part of the research; G.B. - assisted in surface roughness measurements and the interpretation of the vršinske obrade, $s$ nešto većim smanjenjem sjaja na uzorcima obrađenima poliranjem. Smanjenje sjaja uzoraka upućuje na moguće reperkusije na estetiku nadomjestaka, osobito kod uzoraka obrađenih poliranjem.

Promjene u vrijednostima parametara hrapavosti na glaziranim uzorcima izloženima starenju u autoklavu u obliku smanjenja, te na glaziranim uzorcima izloženima korozivnom mediju u obliku povećanja u odnosu prema poliranim uzorcima kod kojih je nastupilo povećanje vrijednosti parametara hrapavosti u oba protokola, upućuju na veće neželjene promjene stanja površine na uzorcima završno obrađenima procesom poliranja.

Završnom obradom nadomjestaka glaziranjem ostvarit će se manji estetski, higijenski i tribološki defekt površine nadomjestaka u odnosu prema završnoj obradi poliranjem.

\section{Sukob interesa}

Autori izjavljuju da nisu bili ni u kakvom sukobu interesa.

\section{Zahvala}

Objavljeni rezultati dio su projekta pod naslovom Definiranje mogucnosti uporabe mini dentalnih implantata (MDI) i njihovi rezultati u in vitro i u kliničkim prospektivnim istraživanjima pod vodstvom prof. dr. sc. Asje Čelebić.

Projekt je financirala Hrvatska zaklada za znanost No. 1218.

\section{Doprinos autora}

K. M. - osmislila istraživanje koje je dio vlastite doktorske disertacije, provela sve eksperimentalne faze istraživanja, napisala članak; I. M. - pomogao pri provedbi mjerenja sjaja površine uzoraka i interpretaciji rezultata tog dijela istraživanja; J. O. - pomogla pri provedbi analize kemijskog sastava uzoraka i interpretaciji rezultata tog dijela istraživanja; G. B. - pomogla pri provedbi mjerenja površinske hrapavosti i interpretaciji rezultata tog dijela istraživanja; K. M. - mentor, savjetnik u svim fazama provedbe i pisanja ovoga rada.
Sažetak

Svrha: Ispitati utjecaj protokola starenja na kemijski i fazni sastav te na kvalitetu površine monolitne translucentne cirkonij-oksidne keramike. Materijali i postupci: Translucentna cirkonij-oksidna keramika KATANA-Zirconia STML s različitom završnom obradom površine (bez obrade, K1, K2; glazirana, G1 - G8; polirana, P1 - P8) podvrgnuta je eksperimentalnim protokolima starenja (hidrotermalna degradacija u autoklavu na $134^{\circ} \mathrm{C}$, pri tlaku od 2 bara tijekom 3 sata: $\mathrm{G} 1-\mathrm{G} 4, \mathrm{P} 1$ - P4 te kemijskoj degradaciji u 4-postotnoj octenoj kiselini na $80^{\circ} \mathrm{C}$ tijekom 16 sati (ISO 6872): G5 - G8, P5 - P8) kako bi se utvrdio njihov utjecaj na kemijski sastav, osobito udio stabilizatora itrijeva oksida (energetsko disperzivna flourescencija X-zraka - EDXRF), fazni sastav (rendgenska difraktometrija - XRD) te stanje površine izraženo hrapavošću i sjajem. Rezultati: Protokoli starenja nisu utjecali na stabilnost kemijskog sastava testiranih uzoraka i visok udio stabilizatora itrijeva oksida ( $\geq 10 \%$ ukupnog udjela) koji je u korelaciji s odsutnošću monoklinske faze. Statistički je značajno smanjenje sjaja površine svih uzoraka. Kemijska degradacija u korozivnom mediju značajno je povećala površinsku hrapavost testiranih uzoraka. Zaključak: Monolitna translucentna cirkonij-oksidna keramika pokazala je stabilnost kemijskog sastava i otpornost na tetragonsko-monoklinsku transformaciju. Sjaj površine značajno je smanjen, osobito na poliranim uzorcima. Suprotno testiranim glaziranim uzorcima, na testiranim poliranim uzorcima uočeno je povećanje hrapavosti površine. Glaziranje površine translucentne monolitne cirkonijeve keramike osigurava bolji estetski, tribološki i higijenski učinak u usporedbi s poliranjem.
Zaprimljen: 1. rujna 2020. Prihvaćen: 2. studenoga 2020.

Adresa za dopisivanje prof. dr. sc. Ketij Mehulić Sveučilište u Zagrebu Stomatološki fakultet Zavod za fiksnu protetiku Gundulićeva 5, HR-10 000 Zagreb tel: +38514802 111 mehulic@sfzg.hr

Ključne riječi

cirkonij; stomatološki materijali; ispitivanje materijala; površinska svojstva; stomatološko poliranje 
Restidseincedsat experimental part of the research; K.M. was a

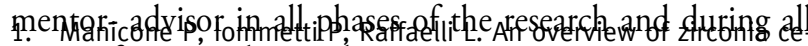
stageanoifsw tianing thopantiess eand clinical applications. J Dent. 2007 Nov;35(11):819-26.

2. Gordan VV, Abu-Hanna A, Mjör IA. Esthetic dentistry in North America dental schools. J Can Dent Assoc. 2004 Apr;70(4):230.

3. Gorman CM, E McDevitt W, Hill RG. Comparison of two-pressed all-ceramic dental materials. Dent Mater. 2000 Nov;16(6):389-95.

4. Heintze SD, Rousson V. Survival of zirconia- and metal supported fixed dental prostheses: a systematic review. Int J Prosthodont. Nov-Dec 2010;23(6):493-502.

5. Stawarczyk B, Jahn D, Becker I, Fischer J, Hämmerle CHF. Einfluss des Gerüstdesigns auf die Bruchlast von $\mathrm{ZrO}_{2}$-Kronen. [Influence of the framework design on the breaking load of $\mathrm{ZrO}_{2}$ crowns]. Quintessenz Zahntech. 2008;34(10):1246-54.

6. Pjetursson BE, Sailer I, Zwahlen $\mathrm{M}$, Hämmerle $\mathrm{CH}$. A systematic review of the survival and complication rates of all-ceramic and metal-ceramic reconstructions after an observation period of at least 3 years. Part I: Single crowns. Clin Oral Impl Res. 2007;18 Suppl 3:73-85.

7. Kohorst P, Borchers L, Strempel J. Low-temperature degradation of different zirconia ceramics for dental applications. Acta Biomater. 2012 Mar;8(3):1213-20.

8. Kawai Y, Uo M, Wang Y. Phase transformation of zirconia ceramics by hydrothermal degradation. Dent Mater J. 2011;30(3):286-92.

9. Chevalier J, Cales B, Drouin JM. Low temperature aging of Y-TZP ceramics. J Am Ceram Soc. 1999;82:2150-4.

10. Lughi V, Sergo V. Low temperature degradation -aging- of zirconia: a critical review of the relevant aspects in dentistry. Dent Mater. 2010 Aug;26(8):807-20.

11. Papanagiotou HP, Morgano SM, Giordano RA, Pober R. In vitro evaluation of low-temperature aging effects and finishing procedures on the flexural strength and structural stability of Y-TZP dental ceramics. J Prosthet Dent. 2006 Sep;96(3):154-64.

12. Kim JW, Covel NS, Guess PC, Rekow ED, Zhang Y. Concerns of hydrothermal degradation in CAD/CAM zirconia. J Dent Res. 2010 Jan;89(1):91-5.

13. Zhenglan L, Danyu J, Lei H, Guoqiang Z, Qiang L, Cheng Z. Low temperature degradation of yttria stabilized zirconia. Mater. 2007;336-8:1188-9.

14. Starwarczyk B, Keul C, Eichberger M, Figge D, Edelhoff D, Lumkemann N. Three generations of zirconia: From veneered to monolithic. Part I. Quintessence Int. 2017;48(5):369-380.

15. Kolakarnprasert N, Kaizer MR, Kim DK, Zhang Y. New multi-layered zirconias: Composition, microstructure and translucency. Dent Mater. 2019;35(5):797-806.

16. Zhang F, Inokoshi M, Batuk M, Hadermann J, Naert I, VanMeerbeek $B$, el al. Strength, toughness and aging stability of highly translucent Y-TZP ceramics for dental restorations. Dent Mater. 2016 Dec;32(12):e327-e337.

17. Tong H, Tanaka CB, Kaiser MR, Zhang Y. Characterization of three commercial Y-TZP ceramics produced for their high translucency. Ceram Int. 2016 Jan 1;42(1 Pt B):1077-1085.

18. Fathy S, El-Fallal A, El-Negoly S, El-Bedawy AB. Translucency of monolithic and core zirconia after hydrothermal aging. Acta Biomater Odontol Scand. 2015 Dec 23;1(2-4):86-92.

19. Sarikaya I, Yerliyurt K, Hayran Y. Effect of surface finishing on the colour stability and translucency of dental ceramics. BMC Oral Health. 2018 Mar 13;18(1):40.

20. Al-Wahadni AM, Martin DM. An in vitro investigation into the wear effects of glazed, unglazed and refinished dental porcelain on an opposing material. J Oral Rehabil. 1999 Jun;26(6):538-46.

21. Ritter AV, Resendiz CV, Henson BR, Culp L, Donovan TE, AmayaPajares SP. Effect of finishing and polishing on the surface rough ness of four ceramic materials after occlusal adjustment. J Esthet Restor Dent. 2016 Nov 12;28(6):382-396.

22. Ancowitz S, Torres T, Rostami H. Texturing and polishing: The final attempt at value control. Dent Clin North Am. 1998 Oct;42(4):60712 , viii.

23. Passos SP, Torrealba Y, Major P, Linke B, Flores-Mir C, Nychka A. In vitro wear behavior of zirconia opposing enamel: a systematic review. J Prosthodont. 2014 Dec;23(8):593-601.
24. Sripetchdanond J, Leevailoj C. Wear of human enamel opposing monolithic zirconia, glass ceramic, and composite resin: an in vitro study. J Prosthet Dent. 2014 Nov;112(5):1141-50.

25. Han GJ, Kim JH, Lee MA, Chae SY, Lee YH, Cho BH. Performance of a novel polishing rubber wheel in improving surface roughness of feldspathic porcelain. Dent Mater J. 2014;33(6):739-48.

26. Stober T, Bermejo JL, Rammelsberg P, Schmitter M. Enamel wear caused by monolithic zirconia crowns after 6 months of clinical use. J Oral Rehabil. 2014 Apr;41(4):314-22.

27. Mundhe K, Jain V, Pruthi G, Shah N. Clinical study to evaluate the wear of natural enamel antagonist to zirconia and metal ceramic crowns. J Prosthet Dent. 2015 Sep;114(3):358-63.

28. Weitmann RT, Eames WB. Plaque accumulation on composite surfaces after various finishing procedures. J Am Dent Assoc. 1975 Jul;91(1):101-6.

29. Chevalier J, Grandjean S, Kuntz M. On the kinetics and impact of tetragonal to monoclinic transformation in an alumina/zirconia composite for arthroplasty applications. Biomaterials. 2009 Oct;30(29):5279-82.

30. Kawai Y, Uo M, Wang Y. Phase transformation of zirconia ceramics by hydrothermal degradation. Dent Mater J. 2011;30(3):286 92.

31. Anusavice KJ. Degradability of dental ceramics. Adv Dent Res. 1992 Sep;6:82-9.

32. Jakovac M, Zivko-Babic J, Curkovic L, Aurer A. Chemical durability of dental ceramic material in acid medium. Acta Stomatol Croat. 2006;40(1):65-7.

33. Šutalo J. Patologija i terapija tvrdih zubnih tkiva. 1st ed. Zagreb: Zadro; 1994.

34. Yoshimura M, Noma T, Kawabata K, Somiya S. Role of water on the degradation process of Y-TZP. J Mater Sci Lett. 1987;6:465-7.

35. Lange FF, Dunlpo GL, Davis BI. Degradation during ageing of transformation toughened $\mathrm{ZrO}_{2}-\mathrm{Y}_{2} \mathrm{O}_{3}$ material at $250^{\circ} \mathrm{C}$. J $\mathrm{Am} \mathrm{Ce}$ ram Soc. 1986;69:237-40.

36. Chevalier J, Gremillard L, Virkar AV, Clarke DR. The tetragonalmonoclinic transformation in zicronia: lessons learned and future trends. J Am Ceram Soc. 2009;92:1901-22.

37. Lee JK, Kim H. Surface crack initiation in 2Y-TZP ceramics by low temperature aging. Ceram Int. 1994;20:413-18.

38. Piconi C, Burger W, Richter HG, Cittadini A, Maccauro G, Covacci $\mathrm{V}$, et al. Y-TZP ceramics for artificial joint replacements. Biomaterials. 1998 Aug;19(16):1489-94

39. Muñoz EM, Longhini D, Gutierres Antonio S, Adabo GL. The effects of mechanical and hydrothermal aging on microstructure on biaxial flexural strength of an anterior and a posterior monolithic zirconia. J Dent. 2017 Aug;63:94-102.

40. Um CM, Ruyter IE. Staining of resin-based veneering materials with coffee and tea. Quintessence Int. 1991 May;22(5):377-86.

41. Turkun LS, Turkun M. Effect of bleaching and repolishing procedures on coffee and tea stain removal from three anterior composite veneering materials. J Esthet Restor Dent. 2004;16(5):290301; discussion 301-2

42. Al-Wahadni A, Martin DM. Glazing and finishing dental porcelain: a literature review. J Can Dent Assoc. 1998;64(8):580-3.

43. Milleding P, Karlsson S, Nyborg L. On the surface elemental com position of noncorroded and corroded dental ceramic materials in vitro. J Mater Sci Mater Med. 2003 Jun;14(6):557-66.

44. Milleding P, Wennerberg A, Alaeddin S, Karlsson S, Simon E. Surface corrosion of dental ceramics in vitro. Biomaterials. 1999 Apr;20(8):733-46.

45. Palla ES, Kontonasaki E, Kantiranis N, Papadopoulou L, Zorba T, Paraskevopoulos KM, et al. Color stability of lithium disilicate ceramics after aging and immersion in common beverages. J Pros thet Dent. 2018 Apr;119(4):632-642.

46. Camposilvan E, Leone R, Gremillard L, Sorrentino R, Zarone F, Ferrari $M$, et al. Aging resistance, mechanical properties and translucency of different yttria-stabilized zirconia ceramics for monolithic dental crown applications. Dent Mater. 2018 Jun;34(6):879-890.

47. Štefančić S. Utjecaj korozivnog medija na strukturu i svojstva dentalnih keramika [dissertation]. Zagreb: Stomatološki fakultet; 2013. 